\section{Surtos de conidiobolomicose ovina por Conidiobolus lamprauges no Estado da Bahia, Nordeste do Brasil}

\author{
Outbreaks of conidiobolomycosis caused by Conidiobolus \\ lamprauges in sheep in the state of Bahia, northeastern of Brazil
}

\section{BJ $\mathrm{M}$}

Brazilian Journal of Veterinary Medicine

p-ISSN 0100-2430 e-ISSN 2527-2179

\begin{abstract}
Tiago da Cunha Peixoto', Eliene Barbosa de Lima², Soraya Santos de Farias ${ }^{3}$, Margareth Moura Ferreira4, Alan Greison Costa Macêdo ${ }^{2}$, Luciano Nakazato ${ }^{5}$, Caroline Argenta Pescador ${ }^{6}$, Mariana Sequeira d'Avila7, Vivian de Assunção Nogueira Carvalho ${ }^{8}$ \& Karina Medici Madureira**
\end{abstract}

'Médicos veterinários, Professores. Escola de Medicina Veterinária e Zootecnia - EMEVZ, Universidade Federal da Bahia UFBA, Salvador, BA, Brasil

²Bolsista MEC. Programa de Residência em Clínica Médica de Ruminantes e Equídeos, Centro do Desenvolvimento da Pecuária - CDP, Universidade Federal da Bahia - UFBA, Santo Amaro, BA, Brasil

${ }^{3}$ Bolsistas MEC. Programa de Residência em Patologia Veterinária, Escola de Medicina Veterinária e Zootecnia - EMEVZ, Universidade Federal da Bahia - UFBA, Salvador, BA, Brasil

${ }^{4}$ Médica veterinária. Centro do Desenvolvimento da Pecuária - CDP, Universidade Federal da Bahia - UFBA, Santo Amaro, BA Brasil

${ }^{5}$ Médico veterinário, Professor. Laboratório de Microbiologia Veterinária e Biologia Molecular Veterinária, Universidade Federal de Mato Grosso - UFMT, Cuiabá, MT, Brasil

${ }^{6}$ Médica veterinária, Professora. Departamento de Clínica Médica Veterinária, Faculdade de Agronomia, Medicina Veterinária e Zootecnia, Universidade Federal de Mato Grosso - UFMT, Cuiabá, MT, Brasil

${ }^{7}$ Médica veterinária. Programa de Pós-graduação em Medicina Veterinária, Instituto de Veterinária - IV, Universidade Federal Rural do Rio de Janeiro - UFRRJ, Seropédica, RJ, Brasil

${ }^{8}$ Médica veterinária, Professora. Departamento de Epidemiologia e Saúde Pública, Instituto de Veterinária - IV, Universidade Federal Rural do Rio de Janeiro - UFRRJ, Seropédica, RJ, Brasil

\section{Resumo}

O presente trabalho descreve a ocorrência de dois surtos de conidiobolomicose em ovinos da raça Santa Inês, no Estado da Bahia. O primeiro surto (PS) ocorreu em uma propriedade localizada no município de Santo Estevão, acometendo três animais, e o segundo surto (SS) em uma propriedade no município de Entre Rios, acometendo um ovino. Em ambos os surtos o quadro clínico caracterizou-se por emagrecimento progressivo, dispneia e descarga nasal serossanguinolenta. No PS observou-se ainda assimetria craniofacial unilateral, associada à exoftalmia e epífora direitas. As necropsias realizadas nos três ovinos do PS evidenciaram grande massa predominantemente branco-amarelada, com áreas vermelho enegrecidas de superfície irregular, finamente granular, úmida e friável localizada na região etmoidal, que invadia a nasofaringe, as coanas, os seios nasais, a região retro bulbar, e se infiltrava na placa cribiforme e alcançava as meninges. Em dois ovinos do PS a massa atingia a porção frontal do cérebro. No ovino do SS verificou-se, na mucosa do vestíbulo nasal pequenos nódulos multifocais a coalescentes, vermelho enegrecidos, com superfície erodida, bem como hiperemia das conchas nasais com secreção catarral hemorrágica e, na porção mais rostral da cavidade nasal, a mucosa encontrava-se com superfície irregular úmida, hemorrágica, vermelha enegrecida com áreas acinzentadas e amarronzadas, exibindo destruição focal parcial das conchas nasais. O exame microscópico das lesões granulomatosas revelou, em geral, múltiplas áreas de necrose de coagulação contendo intensa reação de Splendore-Hoeppli, associadas a imagens negativas de hifas fúngicas e inflamação granulomatosa. Em todos os casos a coloração pelo GMS e PAS evidenciou diversas hifas largas, raramente septadas com dilatação balonosa em uma das extremidades. Por meio da técnica de PCR caracterizou-se Conidiobolus lamprauges, realizada nas amostras de soro de dois ovinos e nas lesões emblocadas em parafina de um ovino. As análises imunohistoquímicas resultaram positivas para C. lamprauges em todos os animais. Comprova-se, pela primeira vez, a ocorrência de conidiobolomicose nasofaríngea/rinocerebral e rinofacial por C. lamprauges no Estado da Bahia.

Palavras-chave: Conidiobolus, zigomicose, rinite micótica, nordeste.

\section{Abstract}

The present work describes the occurrence of two conidiobolomycosis outbreaks in Santa Ines breed sheep, in the state of Bahia. The first outbreak (FO) occurred in a property located in Santo Estevao city, involving three animals, and the second outbreak (SO) occurred in a property in Entre Rios city, affecting one
Como citar: Peixoto, T. C., Lima, E. B., Farias, S. S., Ferreira, M. M., Macêdo, A. G. C., Nakazato, L., Pescador, C. A., d'Avila, M. S., Carvalho, V. A. N., \& Madureira, K. M. (2017). Surtos de conidiobolomicose ovina por Conidiobolus lamprauges no Estado da Bahia, Nordeste do Brasil. Brazilian Journal of Veterinary Medicine, 39(4), 252-263. doi: 10.29374/25272179.bjvm018017

Fonte de financiamento: Recursos próprios, UFBA.

Conflito de interesses: Os autores declaram não haver conflito de interesses que precisam ser informados.

Recebido: Julho 18, 2017

Aceito: Novembro 03, 2017

O estudo foi realizado no Centro de Desenvolvimento da Pecuária - CDP, Escola de Medicina Veterinária eZootecnia, Universidade Federal da Bahia - UFBA, Santo Amaro, BA, Brasil.

\section{${ }^{*}$ Correspondência}

Karina Medici Madureira

Escola de Medicina Veterinária e Zootecnia,

Universidade Federal da Bahia - UFBA

Av. Adhemar de Barros, 500, Ondina

CEP 40170-110 - Salvador (BA), Brasil

E-mail: karina.madureira@ufba.br

Copyright Peixoto et al. Este é um artigo publicado em acesso aberto (Open Access) sob a licença Creative Commons Attribution Non-Commercial, que permite uso, distribuição e reprodução em qualque meio, sem restrições desde que sem fins comerciais e que o trabalho original seja corretamente citado. 
sheep. In both outbreaks, the clinical findings were characterized by progressive weight loss, dyspnea, and bloody serous nasal discharge. In the FO was also observed unilateral craniofacial asymmetry, associated with exophthalmia and epiphora of the right eye. Autopsies performed on the three FO sheep showed a large mass predominantly yellowish-white with red-black areas of the uneven surface, finely granular, moist and crumbly located in the ethmoidal region, invading the nasopharyngeal, choana, sinuses, retro bulbar region, who infiltrated the cribriform plate and reached the meninges. In two sheep of the FO, the mass reached the front portion of the brain. In SO sheep it was found, on the mucous membrane of the nasal vestibule, small red-black multifocal to coalescing nodules, with eroded surface and hyperemia of the nasal turbinates with hemorrhagic catarrhal secretion, and in the most rostral portion of nasal cavity, the mucosa had a irregular, wet, bleeding and red-black surface, with blackish gray and brownish areas, displaying partial focal destruction of nasal turbinates. Microscopic examination of granulomatous lesions revealed multiple areas of coagulation necrosis containing intense reaction of Splendore-Hoeppli associated with negative images of fungal hyphae and granulomatous inflammation. In all cases, the GMS and PAS staining showed numerous wide hyphae, with bulbous distension at one end. By PCR technique it was characterized Conidiobolus lamprauges by analysis of serum samples of two sheep and paraffin block lesions of one sheep. Immunohistochemical analyzes were positive for $C$. lamprauges in all animals. It can be proved, for the first time, the occurrence of nasopharyngeal / rhinocerebral and rhinofacial conidiobolomycosis infection by $C$. lamprauges in the state of Bahia.

Keywords: Conidiobolus, zygomycosis, mycotic rhinitis, northeastern.

\section{Introdução}

A conidiobolomicose é uma doença causada por Conidiobolus spp., um fungo saprofítico oportunista (De Paula et al., 2010; Silva et al., 2010a), normalmente encontrado em regiões de clima tropical e subtropical, em áreas de elevada umidade (Almeid \& Scully, 2002). O fungo tem predileção pelo trato respiratório, mas pode afetar também o coração, musculatura esquelética, rins, cérebro ou promover ainda infecções generalizadas em pacientes imunossuprimidos (Ribes et al., 2000). No homem e em animais, a enfermidade geralmente cursa com grave rinite crônica (De Paula et al., 2010), secundária à intensa infiltração granulomatosa na submucosa nasal, que se estende para o tecido subcutâneo e pele da face (Tadano et al., 2005).

A infecção pelo Conidiobolus spp. pode ocorrer pela inalação dos esporos do fungo encontrados no ambiente (Carrigan et al., 1992) ou pela inoculação direta dos esporos, por meio de micro lesões nas narinas (Ketterer et al., 1992). A ocorrência da doença se concentra nos períodos de maior precipitação pluviométrica, temperatura e umidade altas, condições que permitem o melhor desenvolvimento do agente etiológico (Silva et al., 2007b; Boabaid et al., 2008). A conidiobolomicose possui distribuição mundial e tem sido descrita em ovinos (Ketterer et al.,1992; Carrigan et al.,1992; Morris et al., 2001; Riet-Correa et al., 2003; Silva et al., 2007a; Boabaid et al., 2008; Riet-Correa et al., 2008; Pedroso et al., 2009b; Furlan et al., 2010; Câmara et al., 2011), equinos (Humber et al., 1989), muares (Carvalho et al., 1976), lhamas (Moll et al., 1992) e em seres humanos (Tadano et al., 2005). Em animais, a enfermidade tem sido atribuída à infecção por C. coronatus, C. lamprageus ou C. incongruus (Morris et al., 2001; Silva et al., 2007a).

Em ovinos, a doença geralmente é fatal, com morbidade que varia entre 0,01 e 1\% (Ketterer et al., 1992; Morris et al., 2001; Silva et al., 2007a). No Brasil, a enfermidade tem uma frequência maior em rebanhos ovinos da região Nordeste e Centro-Oeste (Silva et al., 2007a; Silva et al., 2007b; Boabaid et al., 2008; Riet-Correa et al., 2008) e, esporadicamente, em rebanhos do Rio Grande do Sul (Pedroso et al., 2009b) e Santa Catarina (Furlan et al., 2010).

A enfermidade apresenta duas formas clínicas distintas, a rinofacial (Riet-Correa et al., 2003; Silva et al., 2007a; Ubiali et al., 2013) que acomete o vestíbulo nasal, união mucocutânea do nariz, palato duro, lábio superior e pele do focinho (Silva et al., 2007a; Boabaid et al., 2008; Riet-Correa et al., 2008); e a nasofaríngea (Silva et al., 2007a; Ubiali et al., 2013) que afeta a região etmoidal, conchas nasais, seios paranasais, palato mole, faringe, linfonodos regionais, músculos e órbita (Silva et al. 2007a; Riet-Correa et al. 2008), o que pode cursar com assimetria craniofacial, exoftalmia e lesões oculares (opacidade córnea, conjuntivite e cegueira) (Silva et al., 2007a).

As manifestações clínicas incluem apatia, anorexia, dificuldade respiratória, descarga nasal, febre e respiração ruidosa (Silva et al., 2007a; Silva et al., 2010a). 
No Brasil, a doença foi relatada pela primeira vez no Piauí (Silva et al., 2007a) e, posteriormente, na Paraíba (Riet-Correa et al., 2003; Riet-Correa et al.. 2008), Mato Grosso (Boabaid et al., 2008; Ubiali et al., 2013), Rio Grande do Sul (Pedroso et al., 2009b) e Santa Catarina (Furlan et al., 2010). Entretanto, no estado da Bahia, até o momento, não existem descrições dessa doença em ovinos. Visto que a conidiobolomicose provoca grandes perdas econômicas na ovinocultura, pela alta letalidade e gravidade das lesões, aliado à primeira confirmação diagnóstica dessa enfermidade na Bahia, objetivou-se com este trabalho relatar dois surtos de conidiobolomicose em ovinos, causados por Conidiobolus lamprauges.

\section{Histórico}

Foram estudados dois surtos de rinite granulomatosa em ovinos no Estado da Bahia. O primeiro surto (PS) ocorreu em maio de 2013, em uma propriedade localizada no município de Santo Estevão, centro-norte do Estado da Bahia, cujo rebanho era constituído por 51 ovinos da raça Santa Inês, criados em sistema semi-extensivo, cuja pastagem era formada por Brachiaria decumbens e recebiam Pennisetum purpureum picado no cocho. Havia áreas alagadas no pasto onde os ovinos eram mantidos. Nesse surto, três ovinos adultos foram acometidos, sendo duas fêmeas (1PS e 2PS) e um macho (3PS), os quais foram encaminhados ao Centro do Desenvolvimento da Pecuária (CDP), da Universidade Federal da Bahia (UFBA), com histórico de epistaxe por 10 dias, emagrecimento progressivo e aumento de volume do globo ocular, com diagnóstico presuntivo de tumor etmoidal enzoótico. Durante o transporte dos animais ao CDP, um ovino morreu (1PS) e os outros dois animais (2PS e 3PS) permaneceram internados por três dias.

O segundo surto (SS) foi observado em uma propriedade no município de Entre Rios, no Nordeste Baiano, em julho de 2014, sendo acometida uma ovelha, adulta, da raça Santa Inês (1SS), a qual pertencia a um rebanho de 66 ovinos da raça Santa Inês, criados em sistema extensivo, em pastagem composta, predominantemente, por capim-pangola (Digitaria decumbens), embora também houvesse áreas com capim-massai (Panicum maximum cv. Massai) e Brachiaria decumbens. O animal 1SS foi encaminhado ao CDP com histórico de emagrecimento progressivo, acentuada dispneia e intensa descarga nasal serossanguinolenta bilateral, com evolução de seis meses. Havia a suspeita de aspergilose nasal. No CDP, o ovino permaneceu internado por quatro dias e recebeu tratamento sistêmico a base de antibiótico (penicilina) e anti-inflamatório (flunixin meglumine).

Devido ao agravamento do quadro clínico emau prognóstico, em ambos os surtos, os proprietários optaram pela eutanásia in extremis, na tentativa de elucidar a causa da doença. Os quatro ovinos (1PS, 2PS, 3PS e 1SS) foram necropsiados no setor de Patologia do CDP.

Durante as necropsias, foram colhidos fragmentos de massa da região etmoidal, faringe, coanas e encéfalo, além de fragmentos dos pulmões, rins, coração, baço, fígado, linfonodos, olhos e tecidos retrobulbares, intestinos delgado e grosso. Esse material foi fixado em formalina 10\% tamponada com fosfato. Após a fixação, os fragmentos foram processados pela técnica rotineira de inclusão em parafina e corados pelo método de hematoxilina-eosina (HE), prata-metenamina (GMS) e pelo ácido periódico de Schiff (PAS).

Amostras da lesão nasal emblocadas em parafina de todos os ovinos (1PS, 2PS, 3PS e 1SS) e de soro de dois ovinos do primeiro surto (2PS e 3PS) foram enviadas para o Laboratório de Biologia Molecular e Laboratório de Patologia Veterinária da Universidade Federal do Mato Grosso (UFMT), Cuiabá, para caracterização molecular por meio da reação em cadeia da polimerase (PCR) e realização de exames imunohistoquímicos (IHQ), mediante as técnicas descritas por Ubiali et al. (2013), utilizando na IHQ, anticorpo primário policlonal (anti-C. lamprauges) produzido em coelho no Laboratório de Microbiologia e Biologia Molecular da UFMT, bem como anticorpo primário policlonal (anti-P. insidiosum) produzido em coelho no Laboratório de Pesquisas Micológicas da Universidade Federal de Santa Maria (UFSM). Para detecção de C. lamprauges e P. insidiosum utilizou-se o método biotina estreptavidina conjugada com fosfatase alcalina. A recuperação antigênica empregada foi tampão citrato e calor durante três minutos e Proteinase K durante 7 minutos. O anti-C. lamprauges foi diluído em uma concentração de 1:3000, e incubado em estufa a $37^{\circ} \mathrm{C}$ durante três horas. $\mathrm{O}$ anti- $P$. insidiosum foi diluído em concentração de 1:1000. O cromógeno utilizado foi permanente vermelho (Dako) e contra corado com Hematoxilina de Mayer (Pedroso et al., 2009a). 
Adicionalmente, foram colhidas amostras com swab estéril da cavidade nasal do ovino 1SS para exame micológico no Laboratório de Microbiologia Veterinária da Universidade Federal da Bahia (UFBA).

As principais informações relacionadas aos dois surtos relatados neste trabalho estão apresentados resumidamente no Quadro 1.

Ao exame físico realizado no CDP-UFBA, verificaram-se nos ovinos do primeiro surto (PS), em geral, baixo escore de condição corporal, apatia, assimetria facial unilateral, moderada a intensa exoftalmia e moderada epífora direitas, dispneia, secreção nasal serossanguinolenta profusa bilateral, espirros, som maciço à percussão dos seios frontais e, um ovino (3PS) apresentou, pescoço estendido, posição de cavalete e intensa conjuntivite unilateral (Figuras 1 e 2). Observaram-se ainda, linfadenomegalia de submandibulares, pré-escapulares e sub-ilíacos, reflexo pupilar direito diminuído, congestão dos vasos episclerais, compressão da cabeça contra objetos e dismetria.

Já no segundo surto (SS) o ovino exibia clinicamente, além do baixo escore de condição corporal, mucosas pálidas, secreção nasal sanguinolenta profusa bilateral, principalmente após manejo (estresse), respiração predominantemente abdominal enarinas edemaciadas. Observou-se ainda, edema conjuntival bilateral, taquicardia, taquipneia e pescoço estendido.

À necropsia dos três ovinos do PS, evidenciaram-se, após o corte sagital da cabeça, grande massa predominantemente branco-amarelada, com áreas vermelho enegrecidas de superfície irregular, finamente granular, úmida e friável, medindo entre 8,1 × 5,8 cm (ovino 2PS) e 7,7 × 4,6 cm (ovino 3PS), localizada na região etmoidal (Figura 3). A massa invadia a nasofaringe, as coanas, os seios nasais e se infiltrava na placa cribiforme e alcançava as meninges e, nos ovinos 1PS e 3PS, atingia a porção frontal do cérebro. Em algumas áreas, havia extensas áreas de necrose e intensa destruição dos ossos etmoidais, turbinados, das conchas nasais e do septo nasal (rinofaringite proliferativa granulomatosa grave com áreas de necrose). Além disso, nos três ovinos do PS, a massa invadia ainda unilateralmente a região retro bulbar direita, era aderida ao globo ocular e estruturas adjacentes e preenchia grande parte da cavidade orbital (Figura 4), projetando o olho para fora de sua órbita.

No ovino do SS, o exame macroscópico revelou na mucosa do vestíbulo nasal pequenos nódulos multifocais a coalescentes, vermelho enegrecidos, com cerca de 0,5 cm de diâmetro, com superfície ulcerada e, por vezes, com halo hiperêmico. O corte sagital da cabeça evidenciou moderada hiperemia das conchas nasais com leve a moderada secreção catarral hemorrágica nos meatos nasais e, na porção mais rostral da cavidade nasal, verificaram-se mucosa com superfície irregular úmida, hemorrágica, vermelha enegrecida com áreas acinzentadas e amarronzadas (rinite necrohemorrágica), bem como leve destruição focal parcial das conchas nasais, com coágulos aderidos à mucosa ulcerada (Figura 5).

A avaliação histopatológica das massas da região etmoidal, nasofaringe e tecidos retro bulbares dos três ovinos do PS eram constituídas, em geral, por múltiplas áreas de necrose de coagulação, por vezes, coalescentes, contendo intensa reação de Splendore-Hoeppli, onde havia espaços circulares, ovais ou alongados irregulares (imagens negativas de hifas de fungos) (Figura 6), circundadas por intenso infiltrado inflamatório granulomatoso composto, predominantemente, por macrófagos, macrófagos epitelióides, células gigantes multinucleadas, linfócitos e plasmócitos. Observaram-se ainda focos de hemorragia, congestão e proliferação de tecido conjuntivo fibroso, além de intenso infiltrado inflamatório neutrofílico. Adicionalmente, em dois animais do PS (1PS e 3PS), observaram-se no córtex frontal áreas de necrose de liquefação contendo diversas células gitter, focos de gliose e moderada vasculite mononuclear, em outras áreas havia reação granulomatosa com moderada reação de Splendore-Hoeppli, onde se observaram raras hifas. Havia ainda, no pulmão e rim do ovino 1PS e no fígado do ovino 3PS, áreas de necrose com reação de Splendore-Hoeppli, onde se observaram hifas fúngicas, circundadas por inflamação granulomatosa.

No ovino do SS verificaram-se lesões microscópicas idênticas às observadas no PS, porém localizadas na submucosa da porção rostral da cavidade nasal, associadas à pequenos focos de inflamação, menor quantidade de hifas e discretas áreas de hemorragia.

Em todos os casos do PS e SS a impregnação pela GMS e pelo PAS evidenciou a presença de diversas hifas largas, com paredes finas enegrecidas (GMS) ou levemente vermelhas (PAS), raramente septadas com dilatação balonosa em uma de suas extremidades (detalhe da Figura 6). Por meio da técnica de PCR caracterizou-se $C$. lamprauges nas amostras de soro provenientes 


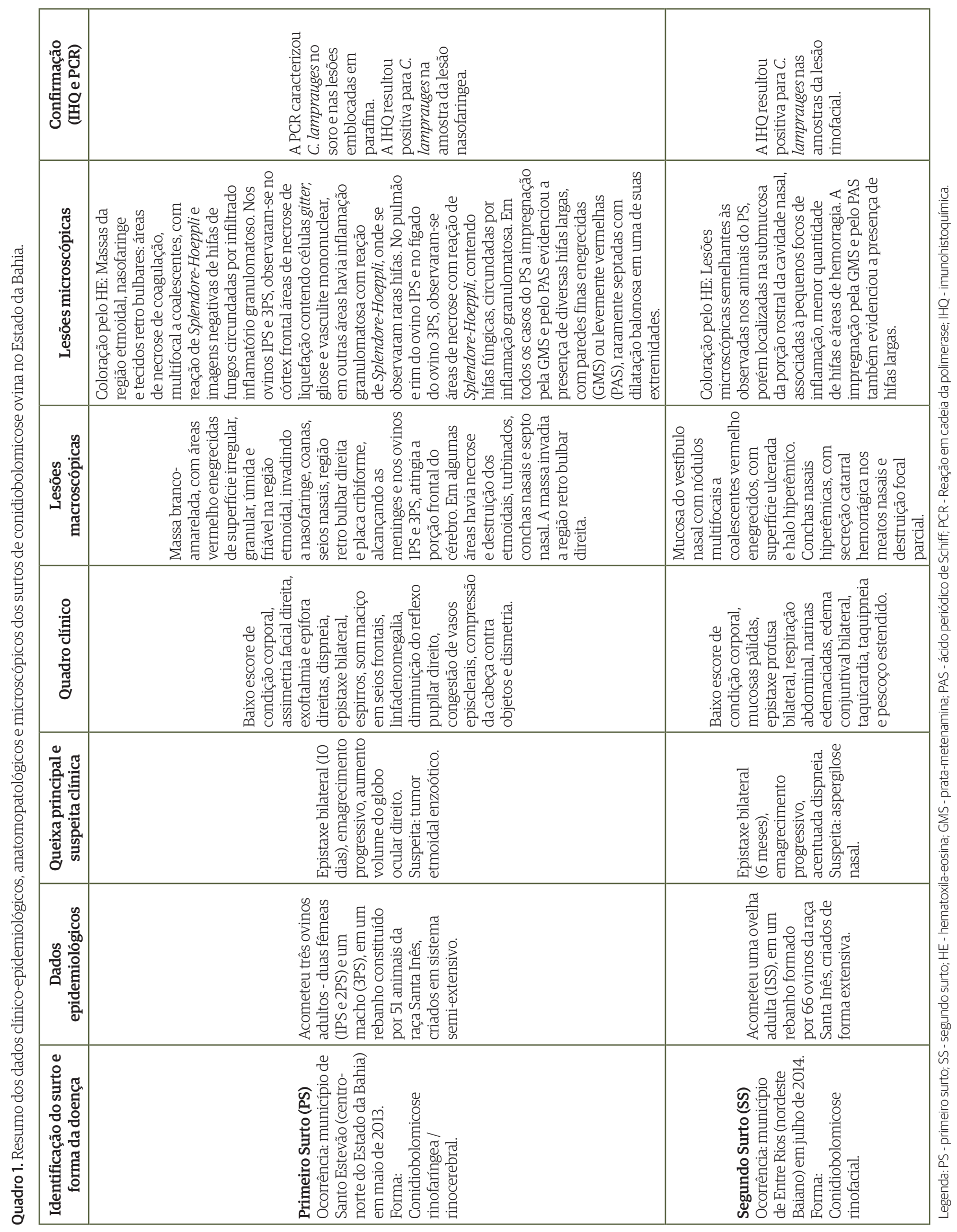




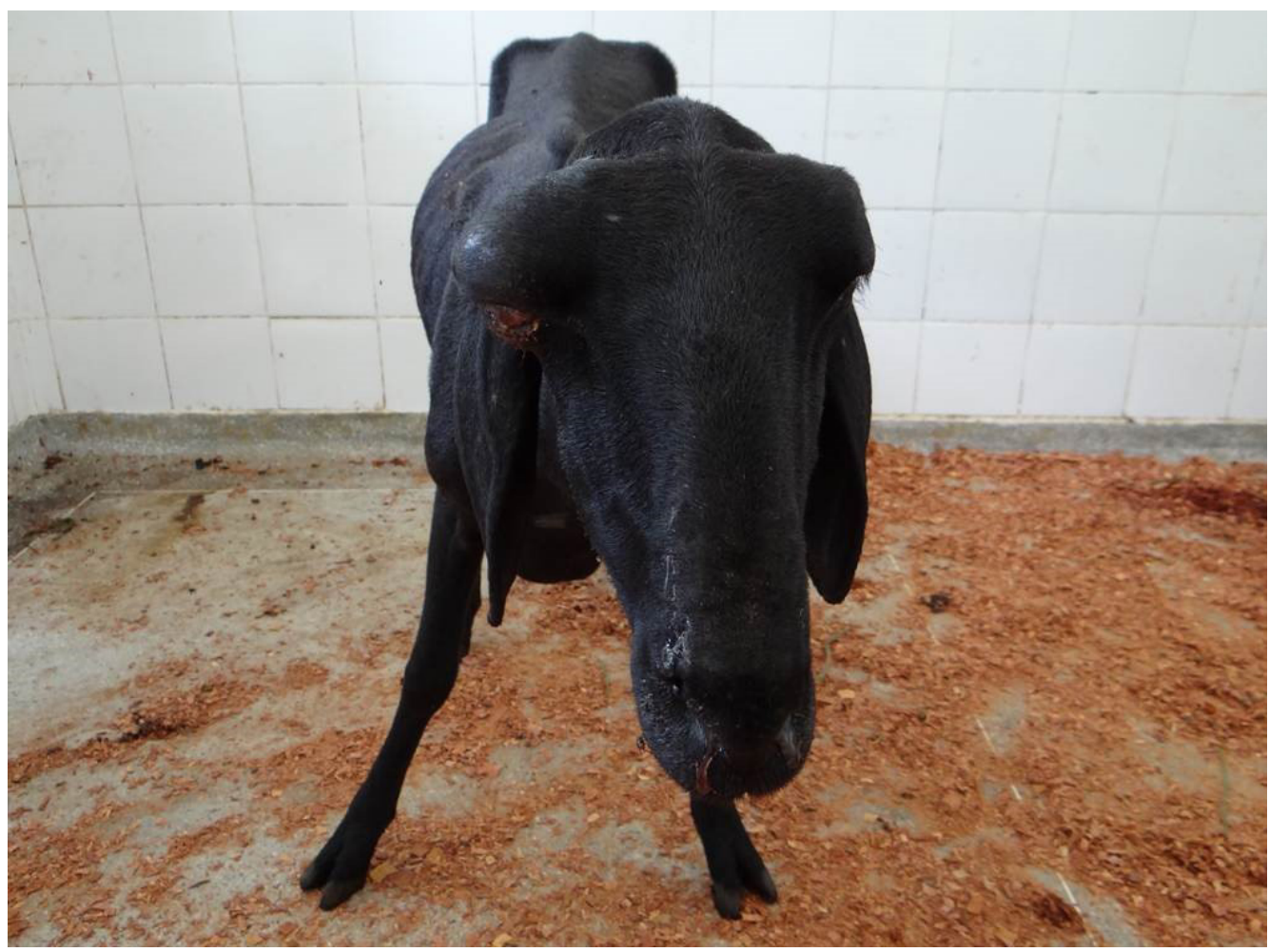

Figura 1. Conidiobolomicose em ovino (2PS). Notar baixa condição corporal, assimetria craniofacial, exolftalmia direita e posição de cavalete.

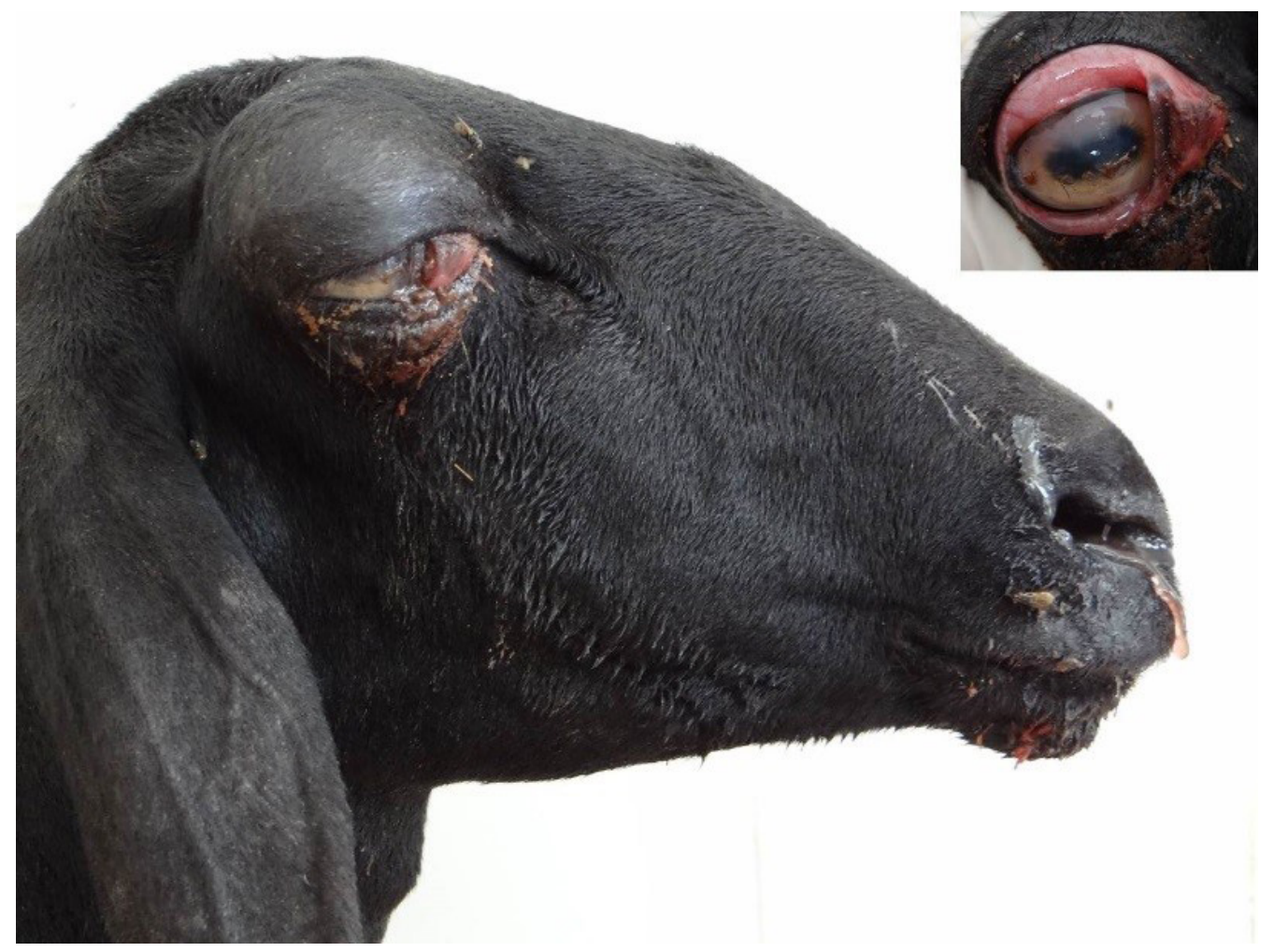

Figura 2. Ovino 2PS acometido por conidiobolomicose exibindo intensa exoftalmia e epífora direita, secreção nasal serossanguinolenta bilateral. No detalhe, hiperemia e edema conjuntival (conjuntivite). 


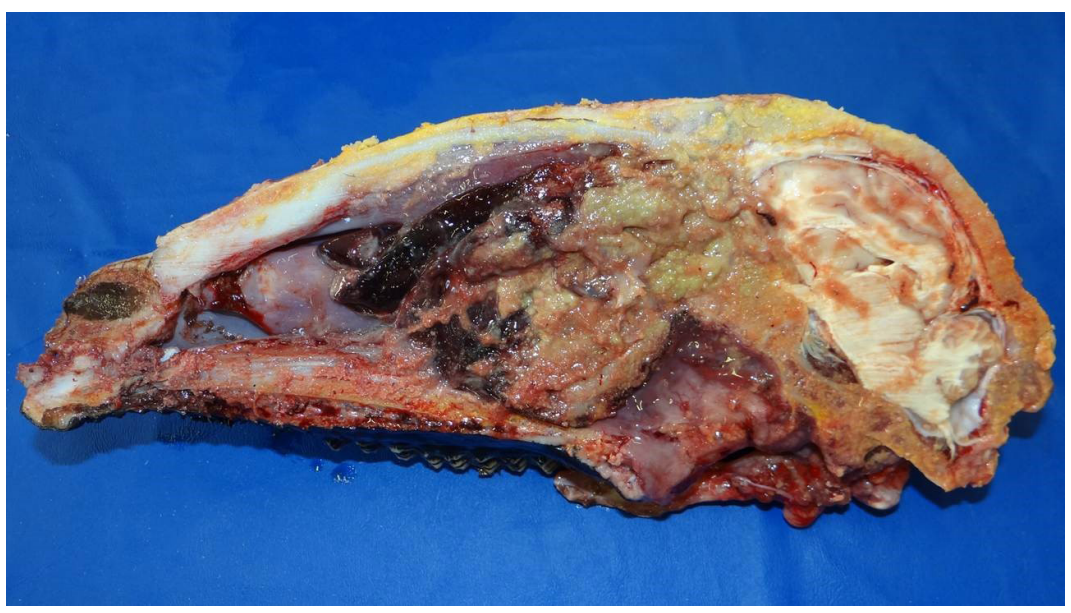

Figura 3. Vista medial do antímero direito da cabeça do ovino 2PS com conidiobolomicose nasofaríngea/ rinocerebral evidenciando grande massa branco-amarelada com áreas vermelho enegrecidas de superfície irregular na região etmoidal.

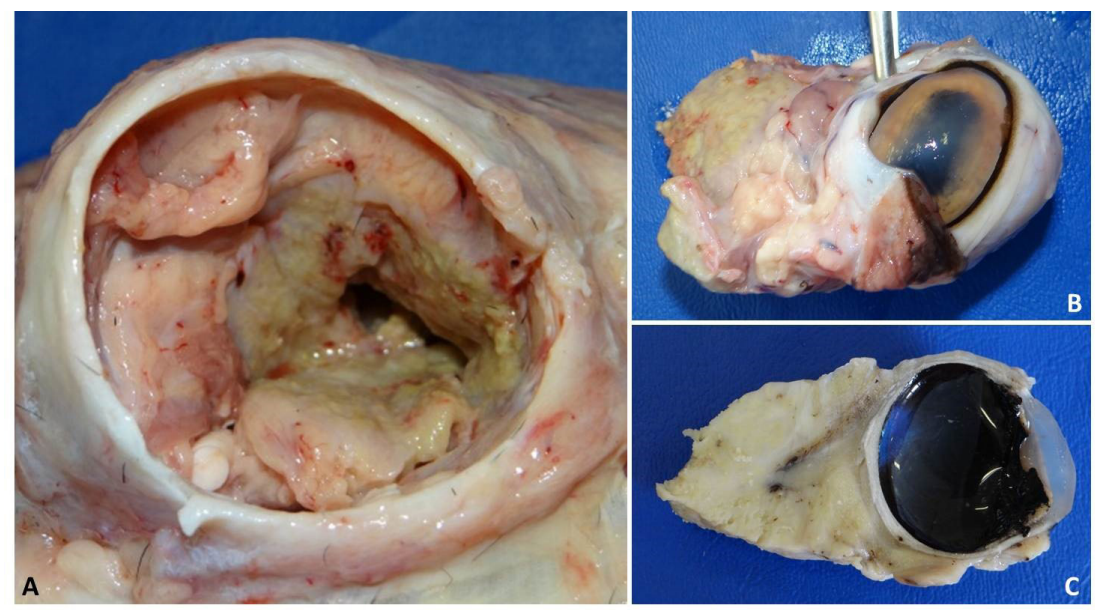

Figura 4. Condiobolomicose em ovinos. Ovino 2PS. (A) Órbita direita. Notar massa amarelada invadindo a cavidade orbital, após a remoção do olho e parte da massa retro bulbar (mostrada em B); (B) Grande massa amarelada aderida ao globo ocular; (C) Superfície de corte da Figura (B) evidenciando a aderência de massa ao globo ocular.

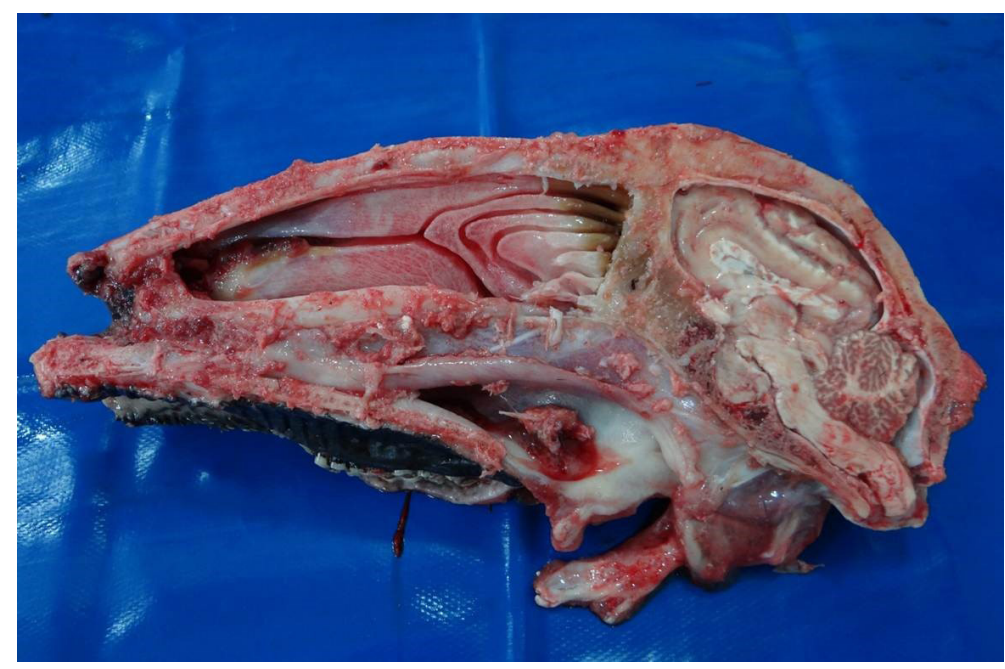

Figura 5. Vista medial do corte sagital da cabeça do ovino 1SS com conidiobolomicose rinofacial. Destruição parcial focal leve da porção rostral da cavidade nasal. 


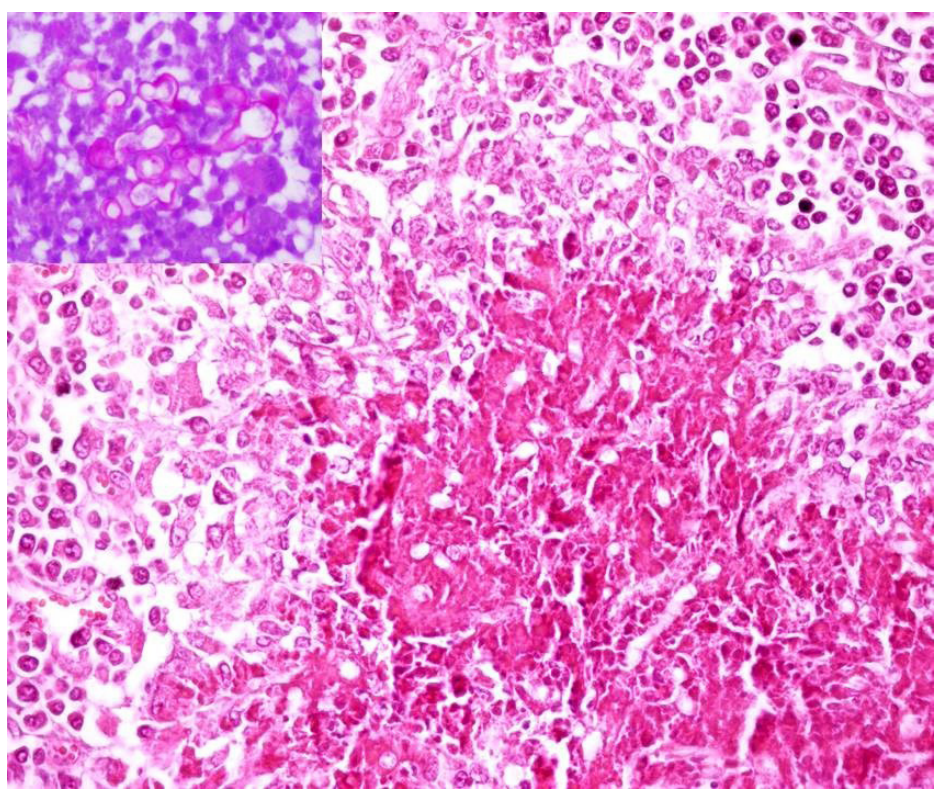

Figura 6. Fotomicrografia da lesão rinofaringea da conidiobolomicose em ovino (2PS). Verifica-se reação de Splendore-Hoeppli com imagens negativas de hifas envoltas por infiltrado inflamatório granulomatoso. HE, obj. 40x. No detalhe, hifas largas, com paredes finas vermelhas com dilatação balonosa em uma de suas extremidades. Ovino 1SS. PAS, Obj. 40x.

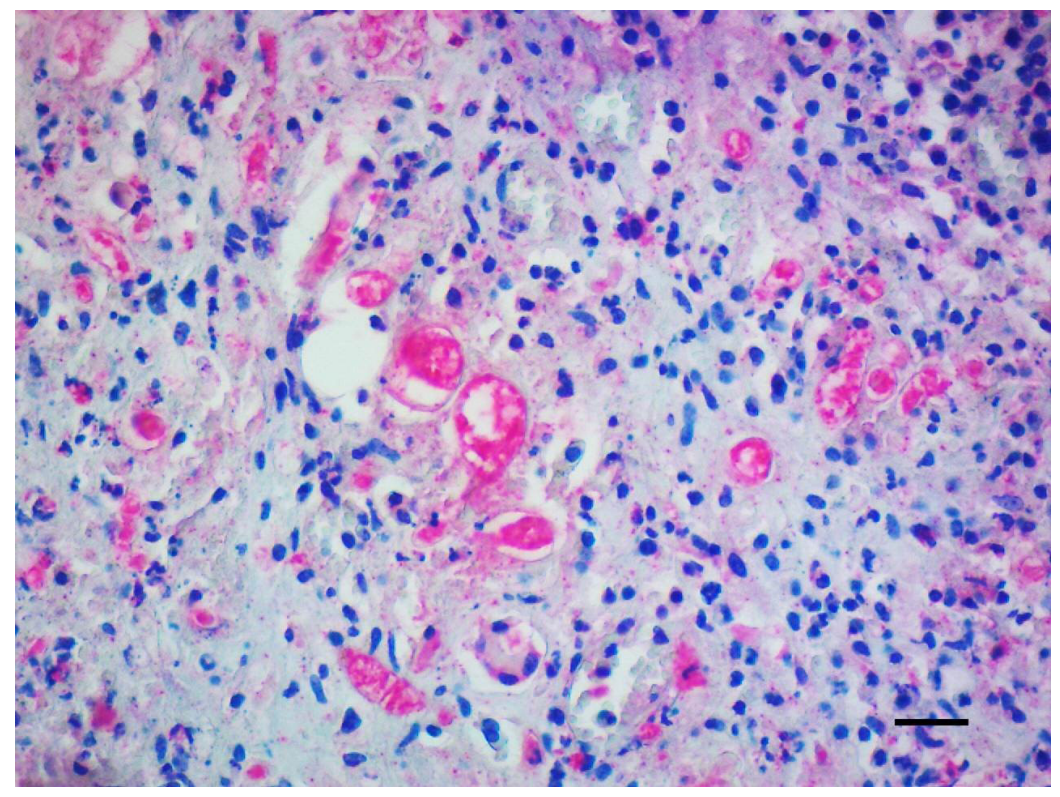

Figura 7. Fotomicrografia da lesão rinofaringea em ovino (1PS) com conidiobolomicose. Marcação imunohistoquímica para C. lamprauges. Obj. 40x. Barra, $10 \mu \mathrm{m}$.

dos dois ovinos do PS (2PS e 3PS), bem como nas lesões emblocadas em parafina do ovino 3PS. As análises imunohistoquímicas resultaram positivas para C. lamprauges (Figura 7) nas amostras dos três ovinos do PS e do ovino do SS. Adicionalmente, os exames IHQs com anti-P. insidiosum, dos mesmos blocos, resultaram negativos em todos os ovinos do PS e SS, bem como a PCR para P. insidiosum a partir do soro e de fragmentos da lesão emblocadas do PS.

Com relação à avaliação micológica das amostras colhidas da lesão nasal do ovino 1SS, a cultura e isolamento fúngico identificaram apenas colônias de Aspergillus niger, o qual foi interpretado como agente contaminante. 


\section{Discussão}

O diagnóstico de conidiobolomicose ocorrido nos dois municípios do estado da Bahia foi estabelecido com base nos dados clínico-epidemiológicos, nos achados macroscópicos, histopatológicos e confirmado por técnicas imunohistoquímicas e PCR. Cabe ressaltar que as duas formas clínicas da doença (rinofacial e nasofaríngea) foram observadas nesse estudo. No surto ocorrido no município de Santo Estevão (PS), a lesão fúngica ocorreu na região nasofaríngea e, em dois casos (1PS e 3PS) atingiu, por extensão, o córtex frontal (conidiobolomicose rinocerebral), devido à invasão da placa cribiforme e cérebro após implantação na cavidade nasal, conforme descrito por Silva et al. (2007a). Entretanto, no SS diagnosticado no município de Entre Rios, verificou-se apenas a forma rinofacial.

A PCR é um importante método para o diagnóstico de várias espécies de fungos devido à sua alta especificidade e sensibilidade (De Paula et al., 2010). Recentemente, Silveira et al. (2013) desenvolveram um teste de PCR específico para C. lamprauges a partir de amostras de lesões de conidiobolomicose ovina. Nesse estudo, a PCR demonstrou elevada sensibilidade (80\%) e especificidade (100\%) na detecção do DNA desse agente micótico em amostras delesões teciduais, proporcionando uma ferramenta rápida para o diagnóstico de C. lamprauges. O diagnóstico definitivo também pode ser obtido pela identificação de antígenos de C. lamprauges pela IHQ, técnica que se mostrou muito útil na detecção e confirmação dos casos de zigomicose nas espécies ovina, bovina, suína e canina (Galiza et al., 2014), fato atribuído à sua capacidade de fornecer um diagnóstico rápido e preciso, em comparação aos cultivos micológicos, que normalmente requerem maior tempo e experiência do micologista (Ubiali et al., 2013). Desta forma, os exames IHQ, PCR ou ambos possibilitaram determinar C. lamprauges como o agente etiológico da doença nos dois surtos aqui relatados.

O quadro clínico verificado nos ovinos do PS e SS foi semelhante ao descrito na literatura para conidiobolomicose ovina, caracterizado por emagrecimento progressivo, exoftalmia, dificuldade respiratória, respiração ruidosa, descarga nasal serossanguinolenta (Silva et al., 2007a; Boabaid et al., 2008; Pedroso et al., 2009b), cabeça baixa, pressão da cabeça contra objetos e incoordenação motora (Silva et al., 2007b; Câmara et al., 2011; Ubiali et al., 2013).

Os achados necroscópicos ora relatados no PS foram semelhantes aos descritos em outros casos da doença no país (Silva et al., 2007a; Boabaid et al., 2008; Pedroso et al., 2009b; Furlan et al., 2010; Silva et al., 2010a; Ubiali et al., 2013), que descreveram massa de coloração amarelada e friável com localização na região etmoidal, conchas nasais e septo nasal característica da forma rinofaríngea da conidiobolomicose. A forma rinofacial afeta o vestíbulo nasal, união mucocutânea do nariz, lábio superior e pele da região anterior da face, com presença de ulcerações na mucosa nasal e no palato duro (Riet-Correa et al., 2008; Silva et al., 2007a; Pedroso et al., 2009b; Aguiar et al., 2014), achados similares ao ocorrido no SS, embora a lesão nasal observada tenha sido inicial (leve).

A avaliação microscópica da rinite granulomatosa demonstrou, em geral, reação de Splendore-Hoeppli com imagens negativas de hifas em meio à áreas multifocais de necrose de coagulação envoltas por marcada inflamação granulomatosa contendo macrófagos epitelióides e células gigantes multinucleadas. Achados semelhantes aos descritos por Furlan et al. (2010), Silva et al. (2010a) e Ubiali et al. (2013) e típicos em infecções micóticas, nas quais há resposta imune mediada por células (Levinson \& Jawetz, 2002).

Embora não tenham sido encontradas descrições de conidiobolomicose em ovinos no estado Bahia, há relatos da doença em outros estados do Nordeste, como Paraíba (Riet-Correa et al., 2008) e Piauí (Silva et al., 2007b). Desta forma, acreditamos que a enfermidade não seja de rara ocorrência no estado, mas que esteja sendo subdiagnosticada e subnotificada ou até mesmo confundida com outras rinites micóticas (pitiose nasal) ou lesões nasais, devido à não realização de necropsias e/ou colheita de material para exames laboratoriais (microbiológicos, histopatologia, IHQ e PCR) para determinação diagnóstica.

De fato, sabe-se que no Piauí a conidiobolomicose foi historicamente, durante muitos anos, diagnosticada erroneamente como tumor etmoidal enzoótico (Nascimento et al.,1979) e que, apenas em 2007, a etiologia correta da doença foi demonstrada por meio de estudos histopatológicos e microbiológicos, os quais revelaram que a doença tratava-se na verdade, de conidiobolomicose (Silva et al., 2007a), o que foi recentemente corroborado por Silva et al. (2010a), que reavaliaram, 
com técnicas histoquímicas e IHQs, três casos previamente diagnosticados como tumor etmoidal enzoótico em ovinos no Piauí e Ceará e confirmaram tratar-se também de conidiobolomicose.

Curiosamente, os ovinos do PS encaminhados ao CDP chegaram com diagnóstico presuntivo de tumor etmoidal enzoótico, ou seja, seria sensato pensar que a doença possa ainda ser confundida com outras enfermidades no estado da Bahia. Além disso, no SS o ovino foi encaminhado ao CDP com suspeita de aspergilose nasal, doença apenas recentemente descrita em cabras na Paraíba (Carmo et al., 2014), o que reforça a nossa hipótese. Tais "diagnósticos equivocados" certamente seriam tidos como corretos e a "ocorrência dessas doenças" seriam propagadas erroneamente pelos pecuaristas. Cabe ressaltar que, no SS por coincidência foi isolado A. niger da lesão nasal, e que este foi interpretado como contaminante da amostra, visto a ausência de hifas com morfologia compatíveis com este agente no exame histopatológico e obviamente pela confirmação de C. lamprauges na IHQ e PCR, o que reforça a importância dessas técnicas para o diagnóstico correto da doença.

Cabe ressaltar que a Bahia possui o segundo maior rebanho ovino do Brasil, com aproximadamente 2.900.000 cabeças (Instituto Brasileiro de Geografia e Estatística, 2014), e que o hábito de pastejo baixo dessa espécie pode favorecer a infecção por meio da inalação dos esporos (Silva et al., 2007b), uma vez que os conídios podem ser ejetados a uma altura de mais de $2 \mathrm{~cm}$ do solo (Humber et al., 1989). Além disso, a ocorrência de surtos da doença pode estar relacionada à alta frequência de chuvas em um período curto, associada com as altas temperaturas observadas na região (Silva et al., 2007b), de fato, tais fatores climáticos ocorreram nos municípios baianos de Santo Estevão e de Entre Rios na época da detecção da doença nos ovinos, sendo inclusive observadas áreas alagadas nas pastagens onde os animais eram mantidos. Desta forma, o estado da Bahia possui condições climáticas e epidemiológicas propícias em certas regiões e épocas do ano para a ocorrência da doença. Entretanto, há relatos da ocorrência da enfermidade no período seco, demonstrando que outros fatores como o pastejo dos animais às margens do açude, com presença de plantas aquáticas e alta pressão de pastejo possam também ser determinantes para a ocorrência da doença (Riet-Correa et al., 2008; Aguiar et al., 2014).

Contudo, é importante realizar o diagnóstico diferencial com tumor etmoidal enzoótico (Pedroso et al., 2009b), uma vez que este apresenta localização anatômica semelhante, entretanto, o curso clínico da doença é mais prolongado e as lesões macroscópicas e histológicas são diferentes (Fernandes, 2007). A conidiobolomicose ovina deve ser diferenciada ainda de outras rinites granulomatosas crônicas, em especial, a pitiose causada pelo oomiceto Pythium insidiosum (Santurio et al., 2008), devido às semelhanças no quadro clínico-patológico. De acordo com Riet-Correa et al. (2008), os achados clínicos da pitiose são semelhantes aos da conidiobolomicose, entretanto, provocam alterações morfológicas diferentes, há reação de Splendore-Hoeppli mais discreta, além de hifas mais finas e com paredes mais espessas. Recentemente Ubiali et al. (2013) descreveram lesões rinofaríngeas causadas por $P$. insidiosum em ovinos, o qual era, até então, associado primariamente à lesões rinofaciais, o que reforça a importância da diferenciação dessas duas enfermidades por exames laboratoriais.

Outra rinite granulomatosa que deve ser diferenciada da conidiobolomicose é a criptococose nasal causada pela levedura encapsulada Cryptococcus neoformans, doença recentemente descrita por Silva et al. (2010b) em uma ovelha da raça Santa Inês, na região semiárida de Pernambuco. Tal diferenciação pode ser facilmente realizada pelo exame histopatológico.

\section{Conclusão}

A rinite granulomatosa de origem micótica observada em ovinos nos municípios de Santo Estevão e Entre Rios, no estado da Bahia, Nordeste do Brasil, trata-se de conidiobolomicose nasofaríngea/rinocerebral e rinofacial, causada por C. lamprauges. Esta é a primeira descrição de conidiobolomicose ovina no Estado da Bahia.

\section{Referências}

Aguiar, G. M. N., Simões, S. V. D., Santos, S. A., Marques, A. L. A., Silva, T. R., Dantas, A. F. M., \& Riet-Correa, F. (2014). Aspectos epidemiológicos da conidiobolomicose em ovinos na região semiárida do Nordeste do Brasil. Ciência Rural, 44(12), 2210-2216. http://dx.doi.org/10.1590/0103-8478cr20131472.

Almeid, O. P., \& Scully, C. (2002). Fungal infections of the mouth. Brazilian Journal of Oral Sciences, 1(1), $19-26$. 
Boabaid, F. M., Ferreira, E. V., Arruda, L. P., Gasparetto, N. D., Souza, R. L., Silva, M. C., Dutra, V., Nakazato, L., \& Colodel, E. M. (2008). Conidiobolomicose em ovinos no Estado de Mato Grosso. Pesquisa Veterinária Brasileira, 28(1), 77-81. http://dx.doi.org/10.1590/S0100-736X2008000100012.

Câmara, A. C. L., Soto-Blanco, B., Batista, J. S., Vale, A. M., Feijó, F. M. C., \& Olinda, R. G. (2011). Rhinocerebral and rhinopharyngeal conidiobolomycosis in sheep. Ciência Rural, 41(5), 862-868. http://dx.doi.org/10.1590/ S0103-84782011005000058.

Carmo, P. M. S., Portela, R. A., Oliveira-Filho, J. C., Dantas, A. F., Simões, S. V., Garino Junior, F., \& Riet-Correa, F. (2014). Nasal and cutaneous aspergillosis in a goat. Journal of Comparative Pathology, 150(1), 4-7. http://dx.doi. org/10.1016/j.jcpa.2013.06.007. PMid:24011904.

Carrigan, M., Small, A., \& Perry, G. (1992). Ovine nasal zygomycosis caused by Conidiobolus incongruous. Australian Veterinary Journal, 69(10), 237-240. http://dx.doi.org/10.1111/j.1751-0813.1992.tb09869.x. PMid:1445069.

Carvalho, E. C. Q., Cruz, J. B., \& Nascimento, R. L. (1976). Rinoficomicose em muar. Pesquisa Agropecuária Brasileira, 11, 13-17.

De Paula, D. A., Oliveira Filho, J. X., Silva, M. C., Colodel, E. M., Broetto, L., Pinto, P. M., Schrank, A., Nakazato, L., \& Dutra, V. (2010). Molecular characterization of ovine zygomycosis in central western Brazil. Journal of Veterinary Diagnostic Investigation, 22(2), 274-277. http://dx.doi.org/10.1177/104063871002200220. PMid:20224092.

Fernandes, C. G. (2007). Tumor enzoótico nasal. In F. Riet-Correa, A. L. Schild, R. A. A. Lemos \& J. R. J. Borges (Eds.), Doenças de ruminantes e equídeos (3. ed., pp. 654). Santa Maria: Pallotti.

Furlan, F. H., Lucioli, J., Veronezi, L. O., Fonteque, J.H., Traverso, S. D., Nakazato, L., \& Gava, A. (2010). Conidiobolomicose causada por Conidiobolus lamprauges em ovinos no Estado de Santa Catarina. Pesquisa Veterinária Brasileira, 30(7), 529-532. http://dx.doi.org/10.1590/50100-736X2010000700003.

Galiza, G. J. N., Tochetto, C., Rosa, F. B., Panziera, W., Silva, T. M., Caprioli, R. A., \& Kommers, G. D. (2014). Utilização de três métodos imuno-histoquímicos na detecção de aspergilose e zigomicose em animais. Pesquisa Veterinária Brasileira, 34(7), 637-642. http://dx.doi.org/10.1590/S0100-736X2014000700005.

Humber, R. A., Brown, C. C., \& Kornegay, R. W. (1989). Equine zygomycosis caused by Conidiobolus lamprauges. Journal of Clinical Microbiology, 27(3), 573-576. PMid:2715329.

Instituto Brasileiro de Geografia e Estatística - IBGE. (2014). Pecuária 2014: rebanho ovino. Rio de Janeiro: IBGE. Recuperado em 3 denovembro de2016, de http://www.bge.gov.br/estadosat/temas.php?sigla=ba\&tema=pecuaria2014

Ketterer, P. J., Kelly, M. A., Connole, M. D., \& Ajello, L. (1992). Rhinocerebral and zygomycosis in sheep caused by Conidiobolus incongruous. Australian Veterinary Journal, 69(4), 85-87.http://dx.doi.org/10.1111/j.1751-0813.1992. tb15556.x. PMid:1605789.

Levinson, W., \& Jawetz, E. (2002). Microbiologia médica e imunologia (7. ed.). Porto Alegre: Artmed. 309 p.

Moll, H. D., Schumacher, J., \& Hoover, T. R. (1992). Entomophthoramycosis conidiobolae in a llama. Journal of the American Veterinary Medical Association, 200(7), 969-970. PMid:1577653.

Morris, M., Ngeleka, M., Adogwa, A. O., Lalla, G., St-Germain, G., \& Higgins, R. (2001). Rhinocerebral zygomycosis in a sheep. The Canadian Veterinary Journal. La Revue Veterinaire Canadienne, 42(3), 227-228. PMid:11265195.

Nascimento, E. F., Reis, R., Carvalho, A. U., Leite, R. C., \& Simplicio, A. A. (1979). Tumor etmoidal enzoótico em ovinos. Arquivos da Escola de Veterinária UFMG, 31(3), 337-342.

Pedroso, P. M. C., Júnior, P. S. B., Pescador, C. A., Dalto, A. G. C., Costa, G. R., Pereira, D. I. B., Santurio, J. M., \& Driemeier, D. (2009a). Diagnóstico imuno-histoquímico de pitiose cutânea em equinos. Acta Scientiae Veterinariae, 37, 49-52.

Pedroso, P., Raymundo, D., Bezerra, J., Oliveira, E., Sonne, L., Dalto, A., \& Driemeier, D. (2009b). Rinite micótica rinofaríngea em um ovino Texel no Rio Grande do Sul. Acta Scientiae Veterinariae, 37, 181-185.

Ribes, J. A., Vanover-Sams, C. L., \& Baker, J. D. (2000). Zygomycetes in human disease. Clinical Microbiology Reviews, 13(2), 236-301. http://dx.doi.org/10.1128/CMR.13.2.236-301.2000. PMid:10756000.

Riet-Correa, F., Dantas, A. F. M., Azevedo, E. O., Simões, S. D. V., Silva, S. M. S., Vilela, R., \& Mendoza, L. (2008). Outbreaks of rhinofacial and rhinopahryngeal zygomycosis in sheep in Paraíba, northeastern Brazil. Pesquisa Veterinária Brasileira, 28(1), 29-35. http://dx.doi.org/10.1590/S0100-736X2008000100005.

Riet-Correa, F., Tabosa, I. M., Azevedo, E. O., Medeiros, R. M., Simões, S. V. D., Dantas, A. F., Alves, C. J., Nobre, V. M. T., Athayde, A. C., Gomes, A. A., \& Lima, E. F. (2003). Doenças de ruminantes e equinos no semi-árido da Paraíba. Semi-Árido em Foco, 1, 2-86.

Santurio, J. M., Argenta, J. S., Schwendler, S. E., Cavalheiro, A. S., Pereira, D. I. B., Zanette, R. A., Alves, S. H., Dutra, V., Silva, M. C., Arruda, L. P., Nakazato, L., \& Colodel, E. M. (2008). Granulomatous rhinitis associated with Pythium insidiosum infection in sheep. The Veterinary Record, 163(9), 276-277. http://dx.doi.org/10.1136/ vr.163.9.276. PMid:18757907.

Silva, S. M. M. S., Castro, R., Costa, F., Vasconcelos, A., Batista, M., Riet-Correa, F., \& Carvalho, E. M. S. (2007a). Conidiobolomycosis in sheep in Brazil. Veterinary Pathology, 44(3), 314-319. http://dx.doi.org/10.1354/vp.443-314. PMid:17491072.

Silva, S. M. M. S., Castro, S., Costa, F., Vasconcelos, A., Batista, M., Riet-Correa, F., Carvalho, E. M. S., \& Lopes, J. B. (2007b). Epidemiologia e sinais clínicos da conidiobolomicose em ovinos no Estado do Piauí. Pesquisa Veterinária Brasileira, 27(4), 184-190. http://dx.doi.org/10.1590/S0100-736X2007000400010. 
Silva, S. M. M. S., Ferreira, L. H., Souza, F. A. L., Nascimento, E. F., Costa, E. A., Paixão, T. A., \& Santos, R. L. (2010a). Conidiobolomicose em ovinos: reavaliação de três casos previamente diagnosticados como tumor etmoidal enzoótico. Arquivo Brasileiro de Medicina Veterinária e Zootecnia, 62(6), 1503-1506. http://dx.doi.org/10.1590/ S0102-09352010000600031.

Silva, S. T. G., Souza, J. C. A., Izael, M. A., Riet-Correa, F., Portela, R., Dantas, A. F., Mendonça, C. L., \& Afonso, J. A. B. (2010b). Nasal cryptococcosis in a sheep in Brazilian Semi-Arid. Brazilian Journal of Veterinary Pathology, 3(2), 127-130.

Silveira, M. M., Paula, D. A. J., Silva, M. C., Pitchenin, L. C., Cruz, R. A. S., Colodel, E. M., Dutra, V., \& Nakazato, L. (2013). Development and application of polymerase chain reaction test for detection of Conidiobolus lamprauges. Pesquisa Veterinária Brasileira, 33(12), 1448-1452. http://dx.doi.org/10.1590/S0100-736X2013001200009.

Tadano, T., Paim, N. P., Hueb, M., \& Fontes, C. J. F. (2005). Entomoftoromicose (zigomicose) causada por Conidiobolus coronatus em Mato Grosso (Brasil): relato de caso. Revista da Sociedade Brasileira de Medicina Tropical, 38(2), 188-190. http://dx.doi.org/10.1590/S0037-86822005000200013. PMid:15821798.

Ubiali, D. G., Cruz, R. A., De Paula, D. A., Silva, M. C., Mendonça, F. S., Dutra, V., Nakazato, L., Colodel, E. M., \& Pescador, C. A. (2013). Pathology of nasal infection caused by Conidiobolus lamprauges and Pythium insidiosum in sheep. Journal of Comparative Pathology,149(2-3),137-145. http://dx.doi.org/10.1016/j.jcpa.2012.12.002. PMid:23375916. 